\title{
Klankontwikkeling van baby's met gehoorverlies
}

\author{
Lizet Ketelaar, Bernadette Vermeij, Conja Adriaanse, \\ Sanne Peet, Wiepke Koopmans
}

NSDSK, Amsterdam

\begin{abstract}
Samenvatting
Doel: Het doel van het huidige onderzoek is zicht te krijgen op het verloop van de klankontwikkeling bij de huidige generatie Nederlandse kinderen met gehoorverlies en te onderzoeken welke factoren van invloed zijn op de klankontwikkeling bij deze groep kinderen.

Methode: De klankontwikkeling van een groep van 28 kinderen met licht tot zeer ernstig perceptief gehoorverlies en van 31 kinderen zonder gehoorverlies is gevolgd over een periode van 12 maanden (leeftijd van 6 tot 18 maanden). Hiervoor werd elke 3 maanden de Infant Monitor of Vocal Production (IMP) afgenomen bij ouders. Daarnaast gaven ouders elke 3 maanden informatie over de hoorontwikkeling van hun kind (LittlEARS) en de draagduur van de hoortoestellen (aanpassing van de Amplification in Daily Life Questionnaire). Ook zijn datalogging gegevens van de hoortoestellen verzameld bij de audiologische centra.

Resultaten: Uit dit onderzoek bleek dat kinderen met gehoorverlies op de leeftijd van 9 maanden een achterstand in de klankontwikkeling lieten zien ten opzichte van hun horende leeftijdsgenoten. Tevens lieten de resultaten zien dat een hogere mate van gehoorverlies leidt tot een minder goede hoorontwikkeling en daarmee een minder goede klankontwikkeling. Kinderen die hun hoortoestel meer droegen hadden een betere hoorontwikkeling.

Conclusie: Op groepsniveau laten kinderen met gehoorverlies in het eerste levensjaar al een achterstand zien in de klankontwikkeling ten opzichte van kinderen zonder gehoorverlies. Er zijn, onder andere als gevolg van de mate van gehoorverlies, echter grote individuele verschillen in het verloop van de klankontwikkeling binnen de groep kinderen met gehoorverlies. Meer onderzoek is nodig om verder vast te stellen welke kinderen met gehoorverlies een groter risico lopen op een achterblijvende klankontwikkeling.
\end{abstract}

\section{Summary}

The aim of this study was to gain insight in the vocal development of the current generation of Dutch children with hearing loss and to examine which factors affect the vocal development of these children. Therefore, the vocal development of a group of 28 children

Correspondentieadres:

Dr. L. Ketelaar

NSDSK

Lutmastraat 167, 1073 GX Amsterdam

E-mail: 1ketelaar@nsdsk.nl
Dit artikel is gelicentieerd onder de Creative Commons CC BY-NC-ND 4.0 (NaamsvermeldingNietCommercieel-GeenAfgeleideWerken) Internationale Licentie. Gebruik en distributie voor commerciële doeleinden en elke distributie van aangepast materiaal vereist schriftelijke toestemming. 
with mild to profound sensorineural hearing loss and of 31 children without hearing loss was monitored over a period of 12 months (age 6 to 18 months). The Infant Monitor of Vocal Production (IMP) was administered to parents every 3 months. In addition, every 3 months, parents reported about their child's hearing development (LittlEARS) and average use time per day of the hearing aids (adaptation of the Amplification in Daily Life Questionnaire). Moreover, data logging values of the hearing aids were obtained from the Audiology Centers. This study showed that the vocal development of children with hearing loss was delayed compared with the vocal development of their hearing peers at the age of 9 months. It was also found that a higher degree of hearing was associated with a delayed hearing development and therefore with a delayed vocal development. Children who wore their hearing aids more, had a better hearing development. At group level, children with hearing loss showed a delayed vocal development compared with children without hearing loss in the first year of life already. However, there were large individual differences, due to degree of hearing loss among other things, in the vocal development trajectories within the group of children with hearing loss. More research is needed to further determine which children with hearing loss are at greater risk of

lagging behind in their vocal development.

\section{Introductie}

\section{Achtergrond en doel van de studie}

Voordat kinderen hun eerste woordjes zeggen, produceren ze al een scala aan klanken. Dit begint met verschillende huilgeluiden en gaat over in vocalisaties die kunnen variëren in bijvoorbeeld luidheid, toonhoogte en duur. Gemiddeld rond de zes maanden volgt bij baby's zonder gehoorverlies de eerste aanzet tot brabbelen: op exploratieve wijze produceren ze hun eerste consonant-vocaal (CV) combinaties. Ongeveer een maand later beginnen ze deze combinaties te herhalen. De combinaties breiden zich langzaam uit tot een variatie van allerlei medeklinkers en klinkers die kinderen vervolgens afwisselend laten horen. Rond de eerste verjaardag verschijnen meestal de eerste echte woorden (Ambrose, Thomas \& Moeller, 2016; Schaerlaekens \& Gillis, 1987). Het oefenen met klanken wordt als een belangrijke basis gezien voor het leren praten, dit geldt ook voor kinderen met gehoorverlies (Koopmans-van Beinum, Clement \& van den Dikkenberg-Pot, 2001; Moeller e.a., 2007; Schaerlaekens \& Gillis, 1987). Als de klankontwikkeling achterblijft, is dit een risicofactor voor de latere gesproken taalontwikkeling (Oller, Eilers, Neal \& Schwartz, 1999). Bekend is dat de taalontwikkeling bij kinderen met gehoorverlies vaak niet optimaal verloopt (Lederberg, Schick \& Spencer, 2013; Tomblin e.a., 2015; Wake, Hughes, Poulakis, Collins \& Rickards, 2004). Aangezien de taalontwikkeling in het eerste jaar al volop in ontwikkeling is door het maken van klanken, brabbels en het gebruik van (proto)woorden, willen we met deze studie in kaart brengen of (en hoe) de klankontwikkeling van kinderen met gehoorverlies verschilt met die van kinderen zonder gehoorverlies. 


\section{Verloop van de klankontwikkeling bij kinderen met gehoorverlies}

In de eerste 6 maanden wordt de klankproductie met name gedreven door anatomische en fysiologische ontwikkelingen. Rond de 7 à 8 maanden zie je in de klankproductie steeds meer de invloed van de zogenaamde 'audition-production loop' terug: kinderen laten onder invloed van auditieve feedback (het horen van gesproken taal in de omgeving) steeds meer variatie in hun klankpatronen horen (Cantle Moore, 2012, 2014; Schaerlaekens \& Gillis, 1987). Aangezien kinderen met gehoorverlies ondanks hun hoorhulpmiddel naar verwachting minder auditieve feedback krijgen, is onze hypothese dat hun klankproductie na 6 maanden uit de pas gaat lopen met die van kinderen zonder gehoorverlies.

Onderzoeken die in het verleden zijn gedaan bij kinderen bij wie het gehoorverlies naar huidige maatstaven laat ontdekt was (i.e., vóór de invoering van de neonatale gehoorscreening), toonden inderdaad een vertraagde klankproductie aan. Er werd bijvoorbeeld een latere start en een lagere frequentie van brabbelen gezien en minder variatie in brabbelgeluiden (Iyer \& Oller, 2008; Koopmans-van Beinum e.a., 2001; Schaerlaekens \& Gillis, 1987). Ook recente internationale onderzoeken bij kinderen bij wie het gehoorverlies wel vroeg is opgespoord, laten een vertraagde klankontwikkeling zien ten opzichte van kinderen zonder gehoorverlies (Ambrose e.a., 2016; Cantle Moore, 2014; Moeller e.a., 2007). In het longitudinale onderzoek van Moeller en collega's (2007) is de klankontwikkeling van kinderen met (matig tot zeer ernstig) en zonder gehoorverlies in de leeftijd van 10 tot 24 maanden elke twee maanden in kaart gebracht. Op basis van opnames van de ouder-kind interactie werd vastgesteld dat de kinderen met gehoorverlies in vergelijking met kinderen zonder gehoorverlies gemiddeld op latere leeftijd startten met herhaald brabbelen en een minder groot repertoire aan consonanten produceerden. Ambrose en collega's (2016) hebben de klankontwikkeling van 74 kinderen van gemiddeld 19 maanden oud met een licht tot ernstig gehoorverlies vergeleken met die van 21 kinderen van dezelfde leeftijd zonder gehoorverlies. Hiervoor hebben zij een instrument, het Vocal Developments Landmark Interview - Experimental Version (VDLI-E) ontwikkeld. Ouders geven op basis van audiofragmenten van verschillende soorten gebrabbel, bijvoorbeeld herhaald gebrabbel (bababa) versus gevarieerd gebrabbel (babiba), aan welk soort gebrabbel hun eigen kind produceert. De kinderen met gehoorverlies lieten op de VDLI-E zien minder ver in hun brabbelontwikkeling te zijn dan de kinderen zonder gehoorverlies. Onderzoek van Cantle Moore (2014) aan de hand van een gestructureerd interview met ouders over de klankontwikkeling van hun kind (met de Infant Monitor of Vocal Production (IMP)), liet hetzelfde beeld zien. De IMP werd drie keer (met een interval van 3-4 maanden) afgenomen bij een groep van 18 kinderen met licht tot zeer ernstig gehoorverlies en 9 kinderen zonder gehoorverlies in de leeftijd van 3 tot 13 maanden. Hieruit bleek dat de kinderen met gehoorverlies vanaf 5 maanden een achterstand hadden in de klankontwikkeling ten opzichte van kinderen zonder gehoorverlies, maar dat zij zich wel in hetzelfde tempo ontwikkelden als de kinderen zonder gehoorverlies. De achterstand bleef dus even groot in het eerste levensjaar.

Uit deze internationale onderzoeken kan geconcludeerd worden dat de klankontwikkeling bij kinderen met gehoorverlies anders verloopt. Dit zou verklaard kunnen worden doordat ze zowel kwalitatief als kwantitatief minder goede auditieve ervaringen hebben dan 
kinderen zonder gehoorverlies, ondanks dat zij reeds op jonge leeftijd een hoortoestel aangemeten krijgen. Als we deze studies afzetten tegen studies waarin gekeken is naar de klankontwikkeling van kinderen met een Cochleair Implantaat (CI), zien we een ander klankontwikkelingspatroon bij kinderen met een CI. Uit die studies bleek namelijk dat er in veel gevallen een kwalitatieve sprong in de klankontwikkeling gezien werd enkele maanden na implantatie, waardoor deze kinderen een inhaalslag maakten in hun ontwikkeling (Ertmer, Young \& Nathani, 2007; Moeller e.a., 2007; Molemans, 2011; Schauwers, Gillis, Daemers, De Beukelaer \& Govaerts, 2004). Daarnaast bleek dat hoe vroeger kinderen een CI kregen, hoe meer hun klankontwikkeling vergelijkbaar verliep met die van kinderen zonder gehoorverlies. Dit benadrukt het belang van vroege auditieve feedback voor het op gang komen van de klankontwikkeling.

Bovenstaande onderzoeken wijzen op een vertraagde klankontwikkeling voor kinderen met gehoorverlies. Meer onderzoek is echter nodig om robuuste conclusies te kunnen trekken. Daarbij is onderzoek in Nederland noodzakelijk om zicht te krijgen op de Nederlandse situatie. De hoorrevalidatie, o.a. de frequentie van controlebezoeken aan het audiologisch centrum en van (gezins) begeleiding, is bijvoorbeeld niet in alle landen even intensief, terwijl bekend is dat deze factoren bijdragen aan een zo optimaal mogelijk verlopende ontwikkeling van het kind (McCreery, Bentler \& Roush, 2013; Walker e.a., 2015). Bovendien is in de genoemde onderzoeken niet gekeken naar factoren die mogelijk van invloed zijn op de klankontwikkeling, zoals de mate van gehoorverlies en het hoorhulpmiddelgebruik.

\section{Factoren die van invloed kunnen zijn op de klankontwikkeling}

Door de invoering van de neonatale gehoorscreening worden gehoorverliezen tegenwoordig al kort na de geboorte opgespoord waardoor bij een blijvend gehoorverlies vroeg gestart kan worden met de hoorrevalidatie. In Nederland krijgen baby's met een gehoorverlies op een gemiddelde leeftijd van 3,7 maanden voor het eerst hoortoestellen aangemeten (Uilenburg \& Van der Zee, 2014). Kinderen die in aanmerking komen voor een CI krijgen in Nederland hun (eerste) CI vaak al rond hun eerste verjaardag. Dankzij de vroege start van interventie en de technologische vooruitgang van hoortoestellen en cochleair implantaten hebben deze jonge kinderen met gehoorverlies in Nederland een betere toegang tot de gesproken taal in vergelijking met kinderen die slechts een decennium eerder geboren zijn en bij wie het gehoorverlies niet is opgespoord door de neonatale gehoorscreening.

Een groot aantal studies heeft reeds aangetoond dat vroege hoorrevalidatie samenhangt met een betere gesproken taalontwikkeling (Boons e.a., 2012; Ching e.a., 2013; Leigh, Dettman, Dowell \& Briggs, 2013; Niparko e.a., 2010; Sininger, Grimes \& Christensen, 2010; Tomblin e.a., 2015; Vohr e.a., 2008), maar of vroege hoorrevalidatie ook leidt tot een betere klankontwikkeling is nog grotendeels onbekend. Uit verschillende onderzoeken blijkt daarnaast dat er veel variatie zit in de gemiddelde draagduur per dag van de hoortoestellen en dat de draagduur toeneemt als kinderen ouder worden (Moeller, Hoover, Peterson \& Stelmachowicz, 2009; Walker e.a., 2013). Alleen als het hoorhulpmiddel frequent en consistent gedragen wordt, heeft een kind optimaal voordeel van een vroege interventie (Walker e.a., 2015). 


\section{Huidige studie}

Deze studie heeft ten doel om: 1) de klankontwikkeling van Nederlandse kinderen met gehoorverlies vanaf 6 maanden tot 18 maanden in kaart te brengen en af te zetten tegen een controlegroep van leeftijdsgenoten zonder gehoorverlies; en 2) te onderzoeken welke factoren, zoals mate van gehoorverlies, hoorhulpmiddelgebruik (leeftijd start hoortoestel en draagduur hoortoestel) en hoorontwikkeling gerelateerd zijn aan de klankontwikkeling van kinderen met gehoorverlies. Met de klankontwikkeling wordt de ontwikkeling van het vermogen tot fonatie en articulatie bedoeld (Ambrose e.a., 2016). Met hoorontwikkeling bedoelen we in deze studie de ontwikkeling van het vermogen om betekenisvolle informatie uit een akoestische omgeving waar te nemen (Litovsky, 2015).

Op basis van de uitkomsten uit internationale studies (Ambrose e.a., 2016; Cantle Moore, 2014; Moeller e.a., 2007) wordt verwacht dat de klankontwikkeling van kinderen met gehoorverlies in de huidige studie zal achterlopen ten opzichte van die van de controlegroep zonder gehoorverlies. Binnen de groep kinderen met gehoorverlies verwachten we dat de relatie tussen de mate van gehoorverlies en de klankontwikkeling verloopt via de hoorontwikkeling (mediatie): een ernstiger mate van verlies zorgt voor minder toegang tot enerzijds de eigen auditieve feedback, anderzijds het taalaanbod vanuit de omgeving (Cantle Moore, 2012, 2014; Schaerlaekens \& Gillis, 1987) en daarmee voor een minder goede hoorontwikkeling, wat vervolgens kan leiden tot een minder goede klankontwikkeling (Figuur 1). Daarnaast verwachten we dat het hoorhulpmiddelgebruik (draagduur en startleeftijd) de relatie tussen de mate van verlies en de hoorontwikkeling beïnvloedt (moderatie) (Walker e.a., 2015). Bij kinderen die hun hoortoestel vanaf jonge leeftijd vaak en consistent dragen heeft de ernst van het gehoorverlies mogelijk een minder grote invloed op de hoorontwikkeling dan bij kinderen die hun hoortoestel minder vaak dragen en/of waarbij het hoortoestel later aangemeten is (Figuur 1).

De uitkomsten van deze studie zullen leiden tot meer inzicht in het verloop van de klankontwikkeling bij de huidige generatie kinderen met gehoorverlies in Nederland. Deze kennis is van belang voor professionals (logopedisten, klinisch linguïsten, gezinsbegeleiders, klinisch fysici-audiologen) die deze kinderen al vanaf jonge leeftijd in zorg hebben. Zij krijgen meer zicht op de vroege klankontwikkeling van de groep jonge kinderen met gehoorverlies, zijn daardoor zelf mogelijk meer alert op de ontwikkeling van de kinderen die zij in zorg hebben en kunnen ouders ook meer bewust maken van de klankontwikkeling van hun kind.

\section{Methode van onderzoek}

\section{Participanten}

In totaal hebben 28 kinderen met gehoorverlies en 31 kinderen zonder gehoorverlies en hun ouders deelgenomen aan dit onderzoek. Als inclusiecriteria voor alle kinderen gold dat ze horende ouders moesten hebben en er thuis (overwegend) Nederlands werd gesproken. In 


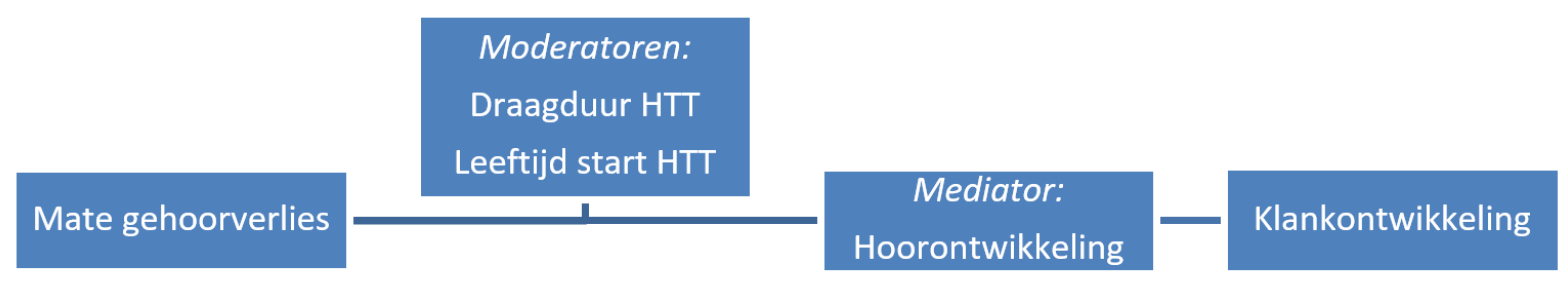

Figuur 1: Verondersteld model van factoren die gerelateerd zijn aan de klankontwikkeling van kinderen met gehoorverlies. Moderator: Een variabele die de sterkte van de relatie tussen twee andere variabelen beïnvloedt. Mediator: Een variabele die de relatie tussen twee andere variabelen verklaart.

de groep kinderen met gehoorverlies hadden alle kinderen een blijvend gehoorverlies. Twee kinderen hadden een gehoorverlies van respectievelijk 36 en $37 \mathrm{~dB}$ in het beste oor, bij de overige kinderen betrof het een verlies van minimaal $40 \mathrm{~dB}$ in het beste oor. Bij het merendeel van de kinderen was er soms $(46 \%, n=13)$ of vaak $(14 \%, n=4)$ sprake van een bijkomend tijdelijk conductief verlies naast het blijvend verlies. Daarnaast was er bij 3 kinderen (11\%) sprake van progressief gehoorverlies. Overige kenmerken van de participanten en hun gezinnen staan in Tabel 1. Exclusiecriterium voor beide groepen was een (vermoeden van) bijkomende problematiek, zoals afwijkingen in de spraakorganen of een cognitieve achterstand. Daarnaast gold voor de groep met gehoorverlies dat kinderen met auditieve neuropathie geëxcludeerd werden. Kinderen die in aanmerking kwamen voor een CI konden meedoen met het onderzoek totdat gestart werd met het afregelen van de CI, waardoor de dataverzameling eerder stopte dan met 18 maanden.

\section{Instrumenten}

\section{Klankontwikkeling}

De IMP is een door het Renwick Centre in Australië ontwikkeld, genormeerd instrument dat de vroege klankontwikkeling van een kind meet tot aan een hoorleeftijd van 12 maanden (Cantle Moore, 2008; Cantle Moore \& Colyvas, 2018). De IMP is specifiek ontwikkeld om de klankontwikkeling van kinderen met gehoorverlies in kaart te brengen. Het betreft een vragenlijst van 16 in ontwikkelingsniveau oplopende vragen die in interviewvorm wordt afgenomen door een getrainde logopedist. Bijvoorbeeld: 'Heeft u gehoord dat uw kind zijn/haar stemgeluid varieert in toonhoogte (omhoog-omlaag)?' $(0=$ nooit, $1=$ zelden, $2=$ soms, $3=$ vaak, $4=$ altijd $)$ of 'Heeft u uw kind twee verschillende klanken horen combineren?' $(0=$ nooit, $1=1$ 2 verschillende klankcombinaties, $2=3-4$ verschillende combinaties, $3=5-6$ verschillende combinaties, $4=6$ of meer verschillende combinaties). Uit onderzoek blijkt dat met behulp van dit instrument de typische klankontwikkeling in kaart gebracht kan worden: oudere, normaal ontwikkelende kinderen die verder waren in hun klankontwikkeling, kwamen verder op de lijst dan jongere, normaal ontwikkelende kinderen (Cantle Moore, 2014). 
Tabel 1: Kenmerken participanten

\begin{tabular}{|c|c|c|}
\hline & $\begin{array}{l}\text { Met gehoorverlies } \\
(\mathbf{n}=\mathbf{2 8})\end{array}$ & $\begin{array}{l}\text { Zonder gehoorverlies } \\
(\mathrm{n}=31)\end{array}$ \\
\hline Jongens, n (\%) & $17(61 \%)$ & $13(42 \%)$ \\
\hline \multicolumn{3}{|l|}{ Etniciteit, n (\%) } \\
\hline Beide ouders geboren in Nederland & $23(82 \%)$ & $31(100 \%)$ \\
\hline Een van beide ouders geboren in Nederland & $3(11 \%)$ & $0(0 \%)$ \\
\hline Beide ouders niet in Nederland geboren & $0(0 \%)$ & $0(0 \%)$ \\
\hline Onbekend & $2(7 \%)$ & $0(0 \%)$ \\
\hline Leeftijd vader in jaren, M (SD) & $34(3,3)$ & $34(5,2)$ \\
\hline \multicolumn{3}{|l|}{ Hoogst genoten opleiding vader, $\mathrm{n}(\%)$} \\
\hline Mavo/MBO & $0(0 \%)$ & $3(10 \%)$ \\
\hline Havo/VWO & $12(43 \%)$ & $12(39 \%)$ \\
\hline $\mathrm{HBO} /$ Universiteit & $14(50 \%)$ & $16(52 \%)$ \\
\hline Onbekend & $2(7 \%)$ & $0(0 \%)$ \\
\hline Leeftijd moeder in jaren, M (SD) & $33(3,7)$ & $33(4,4)$ \\
\hline \multicolumn{3}{|l|}{ Hoogst genoten opleiding moeder, $\mathrm{n}(\%)$} \\
\hline Mavo/MBO & $0(0 \%)$ & $1(3 \%)$ \\
\hline Havo/VWO & $11(39 \%)$ & $7(23 \%)$ \\
\hline $\mathrm{HBO} /$ Universiteit & $15(54 \%)$ & $23(74 \%)$ \\
\hline Onbekend & $2(7 \%)$ & $0(0 \%)$ \\
\hline \multicolumn{3}{|l|}{ Samenstelling gezin, n (\%) } \\
\hline Enig kind & $9(32 \%)$ & $15(48 \%)$ \\
\hline Eén of meer broer(tje)s of zusjes/-sen & $17(61 \%)$ & $16(52 \%)$ \\
\hline Onbekend & $2(7 \%)$ & $0(0 \%)$ \\
\hline \multicolumn{3}{|l|}{ Mate van gehoorverlies in beste oor, $\mathrm{n}(\%)$} \\
\hline Licht (26-40dB) & $3(11 \%)$ & \\
\hline Matig (41-60 dB) & $12(43 \%)$ & \\
\hline Ernstig (61-80 dB) & $5(18 \%)$ & \\
\hline Zeer ernstig (>80 dB) & $5(18 \%)$ & \\
\hline Onbekend & $3^{*}(11 \%)$ & \\
\hline \multicolumn{3}{|l|}{ Gehoorverlies bij overige gezinsleden, $\mathrm{n}(\%)$} \\
\hline Nee & $21(75 \%)$ & \\
\hline $\mathrm{Ja}$ & $5(18 \%)$ & \\
\hline Onbekend & $2(7 \%)$ & \\
\hline
\end{tabular}

${ }^{*}$ Bij deze kinderen was er wel sprake van tenminste $40 \mathrm{~dB}$ gehoorverlies in het beste oor

Het instrument kan herhaald worden afgenomen waardoor de vooruitgang van het kind (ten opzichte van zichzelf) in kaart wordt gebracht. Als een ouder twee opeenvolgende vragen met 'nooit' beantwoordt, stopt de afname. De laatste vraag die door de ouder/verzorger bevestigend beantwoord wordt is de plafondvraag. Bij de volgende meting wordt gestart met 
de vraag voorafgaand aan de plafondvraag.

De IMP is, met toestemming van de auteur, ten behoeve van dit onderzoek volgens de 'translation back-translation' procedure vanuit het Engels naar het Nederlands vertaald. Uit een door ons uitgevoerde pilot met de vertaalde IMP bij 18 kinderen met en zonder gehoorverlies bleek dat de lijst bruikbaar was, als prettig ervaren werd door zowel ouder als logopedist en goed telefonisch af te nemen was. De IMP is niet genormeerd voor het Nederlands.

Om voor dit onderzoek het verloop van de klankontwikkeling in kaart te brengen zijn de bereikte plafondvraag en de variatie in CV-combinaties gebruikt. De plafondvraag laat zien op welk niveau van de klankontwikkeling een kind zich bevindt. De grootte en variatie van het brabbelrepertoire werd in kaart gebracht door ouders te vragen om alle verschillende $\mathrm{CV}$-combinaties op te noemen die door hun kind geuit werden. Hierbij is echter geen onderscheid gemaakt tussen korte en lange klanken zoals de a en aa. Ter illustratie, wanneer deze klanken beide gecombineerd werden met de $\mathrm{m}$ (ma en maa), werd dit één keer meegeteld als CV-combinatie.

\section{Mate van gehoorverlies en hoorontwikkeling}

De mate van gehoorverlies werd opgevraagd via de audiologische centra waar de kinderen kwamen. De audiologische centra werden gevraagd om een beste schatting op basis van de gemiddelde gehoordrempel (Pure Tone Average (PTA)) bij 0.5, 1, 2 en $4 \mathrm{kHz}$ te geven voor zowel het linker- als het rechteroor, zonder eventuele conductieve component. Vervolgens werd de PTA in het beste oor genomen als indicatie van de mate van gehoorverlies. Kinderen werden op basis van deze maat gecategoriseerd in een van de categorieën van gehoorverlies (zie Tabel 1).

De hoorontwikkeling is gemeten met de LittlEARS (Kühn-Inacker, Weichbold, Tsiakpini, Coninx \& D'Haese, 2003), een gevalideerde vragenlijst om de auditieve ontwikkeling van normaal horende baby's en peuters in kaart te brengen (Coninx e.a., 2009). De lijst bevraagt de ontwikkeling van verschillende vaardigheden van verstaan, zoals het detecteren, discrimineren, identificeren en begrijpen van geluiden en/of spraak. De LittlEARS meet de hoorontwikkeling van kinderen met een hoorleeftijd van 0 tot 24 maanden en is bij elk meetmoment ingevuld door ouders. De vragenlijst bestaat uit 35 vragen over de het begrip van geluiden en de reactie die het kind geeft op verschillende geluiden zoals stemmen, muziek en objecten. Bijvoorbeeld: 'Reageert het kind met ritmische bewegingen op muziek?' Bij volgende metingen werd gestart bij de eerste vraag waar ouders de vorige keer nee op hadden geantwoord.

\section{Gebruik hoorhulpmiddelen}

Het gebruik van hoorhulpmiddelen is bij elk meetmoment telefonisch nagevraagd bij ouders met behulp van een aanpassing van de Amplification in Daily Life Questionnaire (Moeller e.a., 2009). Er werd gevraagd naar de draagduur in uren voor elk van de dagen van de week, op basis waarvan een gemiddelde draagduur per dag werd berekend.

Daarnaast zijn datalogging gegevens over de gemiddelde draagduur opgevraagd bij de audiologische centra. Wanneer het moment van datalogging voldoende samenviel $(+/-1$ maand) met een van de meetmomenten, zijn deze gegevens opgenomen in het databestand. 
Tabel 2: Aantal participanten per groep, per meetmoment

\begin{tabular}{llllll}
\hline Groep & $\mathbf{6}$ mnd & $\mathbf{9}$ mnd & $\mathbf{1 2}$ mnd & $\mathbf{1 5}$ mnd & $\mathbf{1 8}$ $\mathbf{n d}$ \\
\hline Met gehoorverlies & 23 & 27 & 18 & 7 & 2 \\
Zonder gehoorverlies & 29 & 31 & 27 & 10 & 2 \\
\hline
\end{tabular}

Tot slot is bij de audiologische centra voor elk kind ook de datum opgevraagd waarop gestart is met gebruik van het hoortoestel.

\section{Procedure}

Voorafgaand aan de start van het onderzoek is bij de METC Noord-Holland getoetst of het onderzoek onder de reikwijdte van de WMO viel, maar het onderzoek bleek niet WMOplichtig. Ouders van kinderen zonder gehoorverlies zijn geworven via twee centra voor Jeugd en Gezin, een kinderdagverblijf en het eigen netwerk van de onderzoekers. De kinderen met gehoorverlies zijn geworven via audiologische centra en gezinsbegeleidingsdiensten uit heel Nederland. Alle ouders zijn schriftelijk geïnformeerd over het doel en de methoden van het onderzoek, de belasting, privacy en vrijwilligheid van deelname. Ze hebben allen toestemming gegeven voor deelname aan het onderzoek. Ouders van kinderen met gehoorverlies hebben daarnaast toestemming gegeven voor het opvragen van audiologische gegevens bij het audiologisch centrum.

Bij beide groepen kinderen zijn op vaste momenten data verzameld, namelijk op de leeftijd van $6,9,12,15$ en 18 maanden (+/- 2 weken). Het merendeel van de kinderen was 6 maanden oud bij aanvang, enkele kinderen zijn ingestroomd bij 9 maanden. Daarnaast zijn afnames bij meerdere kinderen gestopt voor de leeftijd van 18 maanden, omdat: 1) ouders wilden stoppen wegens persoonlijke redenen ( 1 kind met en 1 kind zonder gehoorverlies); 2) de kinderen op een eerdere leeftijd het einde van de IMP hadden bereikt (6 kinderen met en 27 kinderen zonder gehoorverlies); 3) kinderen pas tegen het einde van de dataverzamelingsperiode geworven waren waardoor zij niet meer voor alle meetmomenten gevolgd konden worden (10 kinderen met gehoorverlies); of 4) kinderen een CI kregen (6 kinderen met gehoorverlies). In tabel 2 staat een overzicht van het aantal kinderen, uitgesplitst naar groep en meetmoment.

\section{Resultaten}

\section{Ontwikkelingspatronen en groepsverschillen plafondvraag}

Voor de groepen kinderen met en zonder gehoorverlies is op individueel niveau gekeken naar het verloop van de klankontwikkeling. Er bleek in beide groepen veel individuele vari- 
atie te zijn wat betreft het verloop en het niveau van de klankontwikkeling (i.e. de bereikte plafondvraag). In Figuur 2 zijn de individuele trajecten van respectievelijk kinderen uit de groep met en de groep zonder gehoorverlies te zien. Hieruit blijkt dat de groep zonder gehoorverlies over het algemeen een homogener beeld liet zien dan de groep met gehoorverlies. In de laatstgenoemde groep was het verloop over de tijd heen meer divers. Zo waren er in de groep met gehoorverlies bijvoorbeeld 7 kinderen bij wie het niveau gelijk bleef of afnam tussen de 6 en 9 maanden, terwijl er maar 1 kind zonder gehoorverlies was bij wie het niveau gelijk bleef in die leeftijdsperiode.
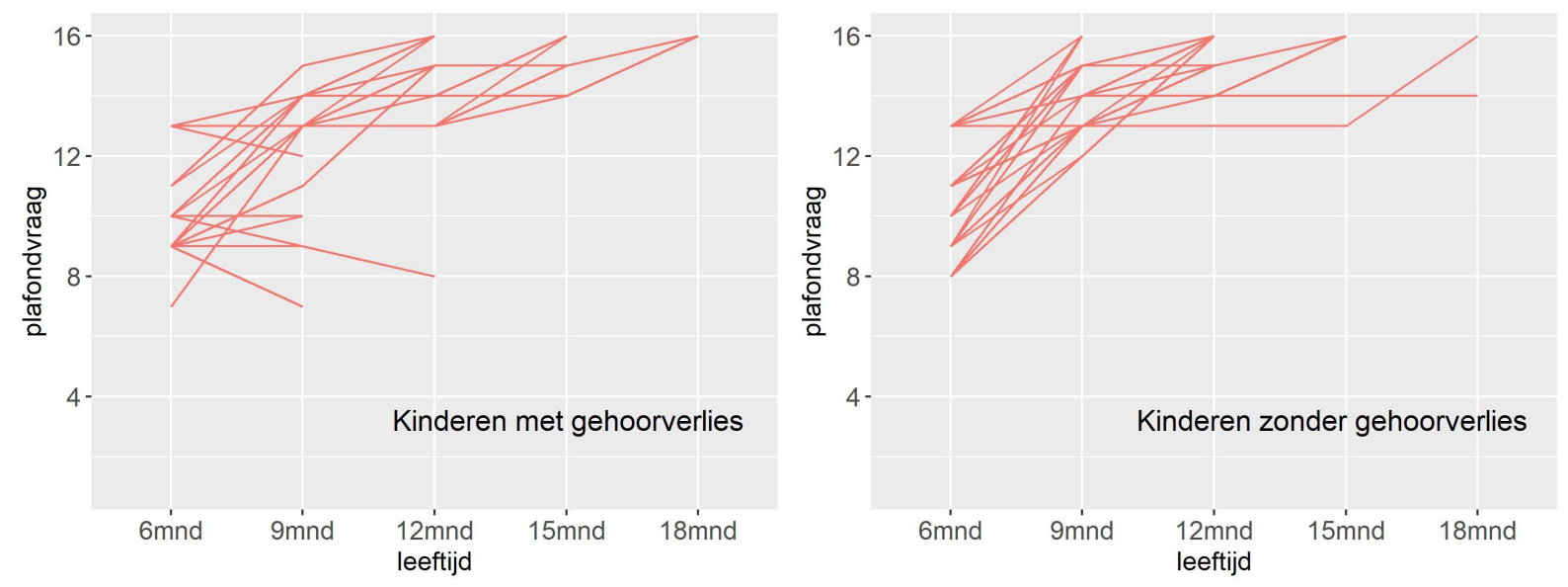

Figuur 2: Verloop van de klankontwikkeling (i.e. bereikte plafondvraag op de IMP) bij kinderen met gehoorverlies (links) en zonder gehoorverlies (rechts).

Daarnaast is binnen de groep kinderen met gehoorverlies het verloop van de klankontwikkeling uitgesplitst naar de mate van gehoorverlies en draagduur (Figuur 3). Hoewel de aantallen kinderen in de verschillende categorieën te klein zijn om hier conclusies aan te verbinden, geven deze grafieken wel een goed beeld van de variatie die kinderen laten zien in hun klankontwikkeling.

Omdat bij veel kinderen geen data meer verzameld is na de leeftijd van 12 maanden zijn verdere analyses alleen voor de eerste drie meetmomenten uitgevoerd. Er is onderzocht of er op deze drie meetmomenten een verschil was tussen kinderen met en zonder gehoorverlies op de plafondvraag (de laatste vraag die door ouders bevestigend beantwoord werd). Uit t-toetsen voor onafhankelijke steekproeven bleek dat er alleen op 9 maanden een groepsverschil was wat betreft de plafondvraag die bereikt werd $t(40.14)=-4.05, p<.001$. Kinderen zonder gehoorverlies kwamen op deze leeftijd gemiddeld bijna twee vragen verder dan kinderen met gehoorverlies (zie Figuur 4). 

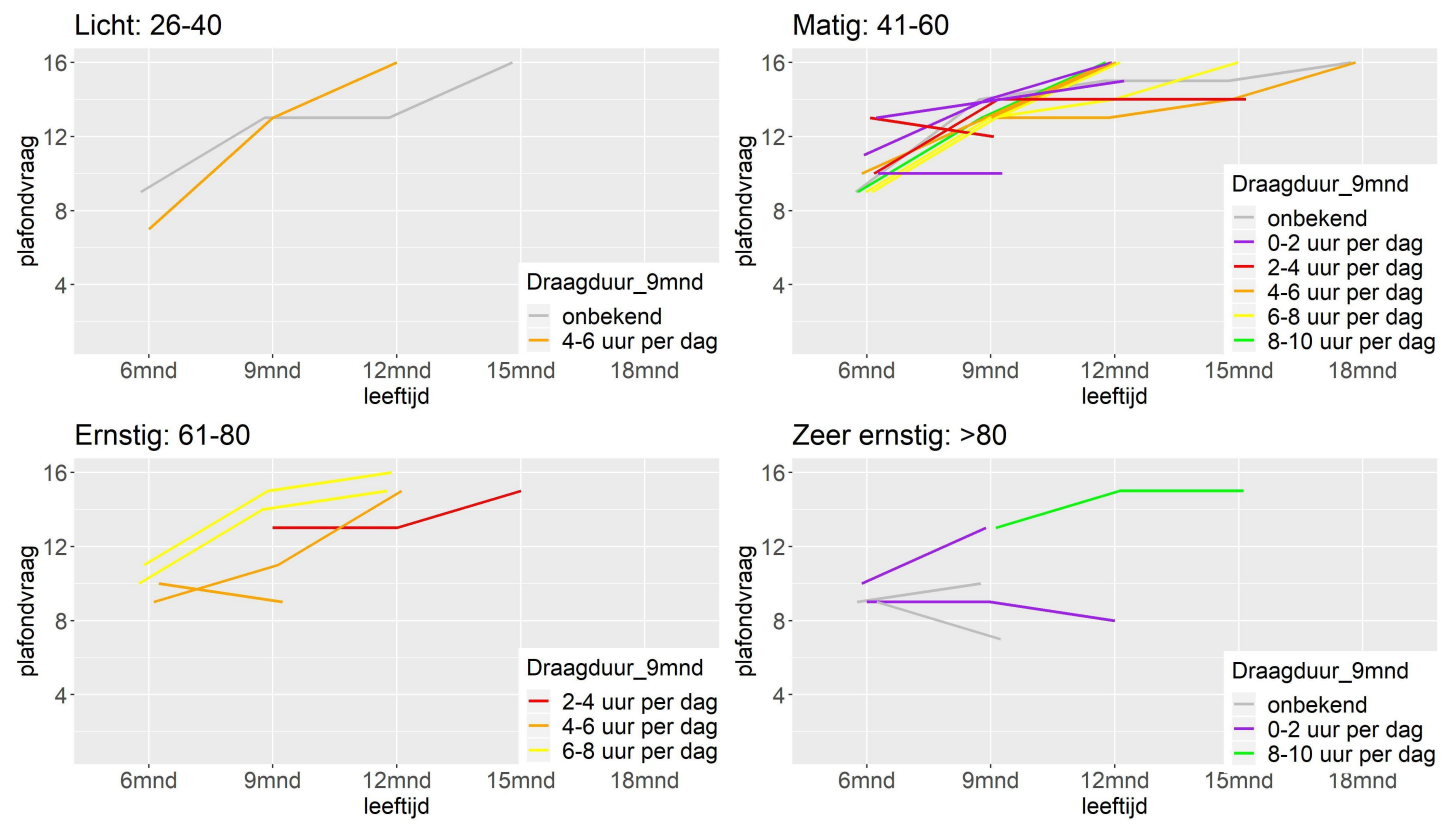

Figuur 3: Verloop van de klankontwikkeling, uitgesplitst naar mate van gehoorverlies (licht - zeer ernstig) en gemiddelde draagduur per dag van de hoortoestellen (op de leeftijd van 9 maanden).

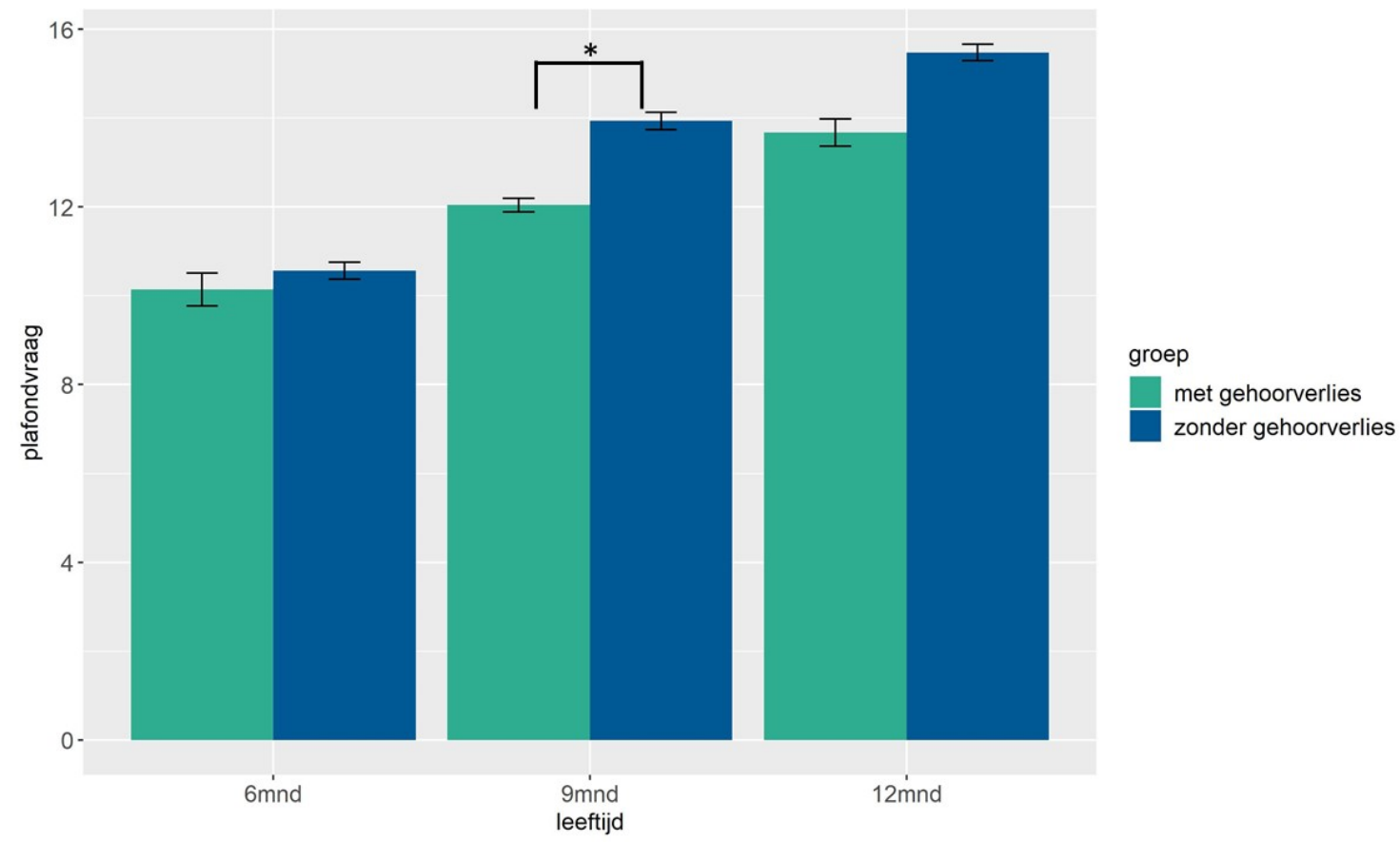

Figuur 4: Groepsverschillen bereikte plafondvraag IMP op de eerste drie meetmomenten.

$$
* p<.001
$$




\section{Groepsverschillen consonant-vocaal combinaties}

Vervolgens is per kind geregistreerd welke losse consonanten en vocalen geuit werden in de CV-combinaties die zij volgens ouders produceerden. Om meer zicht te krijgen op dit verschil in klankvariaties is van de vroeg verworven vocalen en consonanten (Beers, 2003; Schaerlaekens \& Gillis, 1987) in kaart gebracht of de kinderen deze al gebruikten. Per groep is het percentage kinderen bepaald dat deze klanken produceerde op 6, 9 en 12 maanden (Figuur 5 en 6). In deze figuren is te zien dat de individuele klanken, zowel de consonanten als de vocalen, bijna allemaal minder geproduceerd leken te worden door de groep kinderen met gehoorverlies. Echter, uit t-toetsen voor onafhankelijke steekproeven bleek na Bonferroni correctie dat wat betreft de individuele vocalen alleen de $i$ /ie op 9 maanden significant minder geproduceerd werd door de groep met gehoorverlies $(t(47)=-3.10, p=.003)$, de overige verschillen waren niet significant. Voor de individuele consonanten gold dat geen enkel verschil meer significant was na Bonferroni correctie. Wanneer getoetst werd op het gemiddeld aantal consonanten per kind, bleken kinderen met gehoorverlies op zowel 6, 9 als 12 maanden minder consonanten te produceren dan kinderen zonder gehoorverlies (resp. $t(52)=-2.03, p=.047 ; t(57)=-2.80, p=.007 ; t(47)=-2.33, p=.024)$. Voor het gemiddeld aantal vocalen werd alleen op 9 maanden een verschil geobserveerd $(t(57)=-2.68, p=.010)$, in het nadeel van kinderen met gehoorverlies. Daarnaast lieten kinderen met gehoorverlies op zowel 6, 9 als 12 maanden een lager aantal verschillende CV-combinaties horen dan kinderen zonder gehoorverlies (resp. $t(52)=-2.04, p=.046 ; t(57)=-3.28, p=.002 ; t(47)=-2.43$, $p=.019$ ).

Wanneer we specifieker kijken naar de verwervingsvolgorde zien we overeenkomsten tussen beide groepen. Zo was de $a / a a$ bijvoorbeeld in beide groepen de vocaal die al vroeg door veel kinderen geproduceerd werd, terwijl de $o / o o$ in beide groepen wat later lijkt te ontwikkelen. Ook voor de consonanten zien we overeenkomsten tussen de groepen. De $k, t$ en $n$ lijken in beide groepen over het algemeen later geproduceerd te worden dan de andere consonanten.

\section{Hoorhulpmiddelgebruik}

Er is op basis van ouderrapportage en datalogging gegevens inzicht verkregen in hoeveel uur per dag kinderen hun hoortoestel gemiddeld gedragen hadden (zie Tabel3). Met behulp van correlaties is onderzocht in hoeverre de ouderrapportages en datalogging gegevens met elkaar overeen kwamen. Er bleek sprake van een matig tot sterk verband $(\mathrm{r}=.41, .70$ en .64 op respectievelijk 6, 9 en 12 maanden).

\section{Relaties tussen mate van gehoorverlies, hoorontwikkeling, klankontwik- keling en hoorhulpmiddelgebruik}

De relaties tussen de mate van gehoorverlies, de klankontwikkeling (gemeten met de plafondvraag) en de hoorontwikkeling (gemeten met de LittlEARS) zijn onderzocht. Hierbij is 


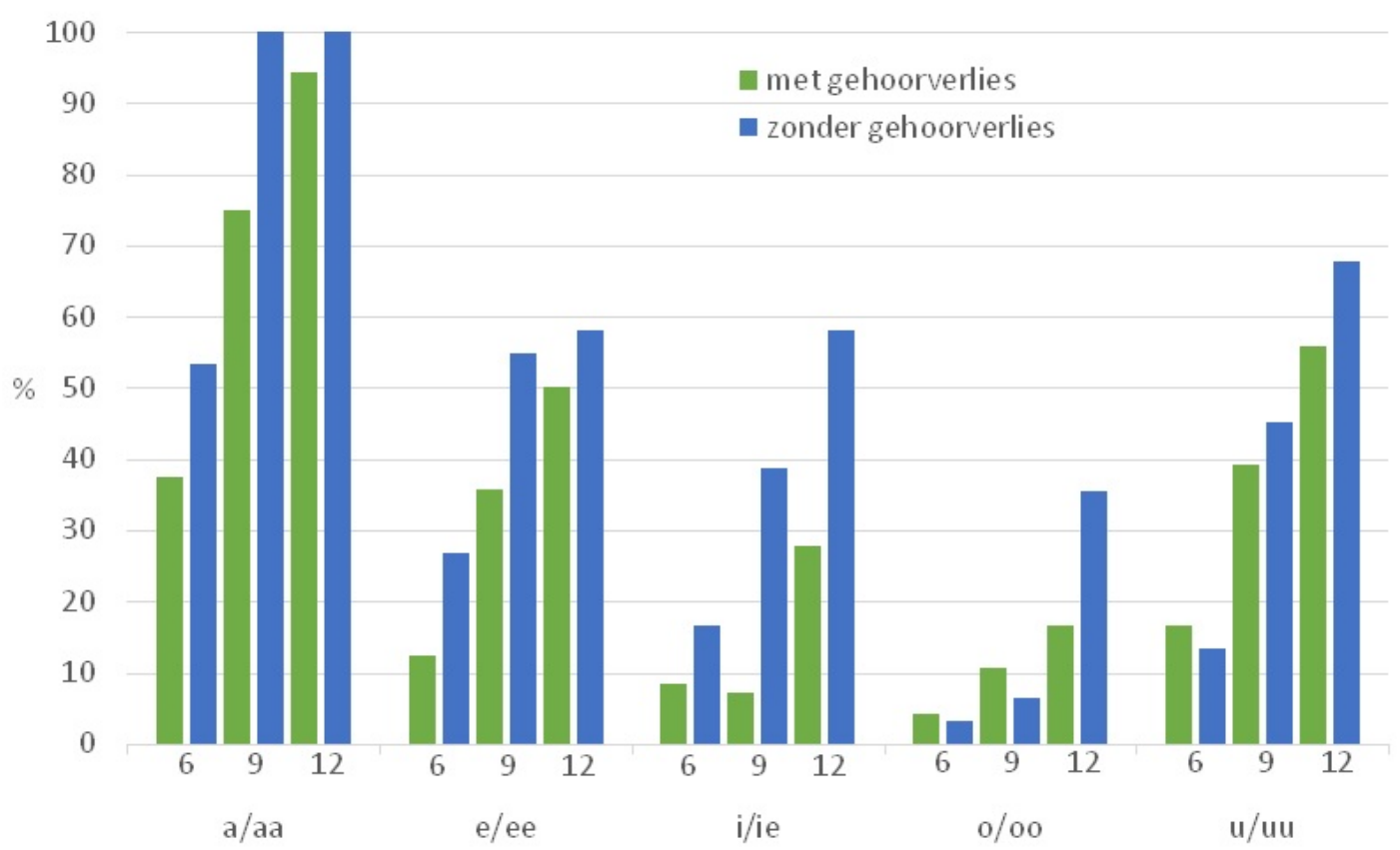

Figuur 5: Percentage kinderen dat vocalen produceerde op 6, 9 en 12 maanden.

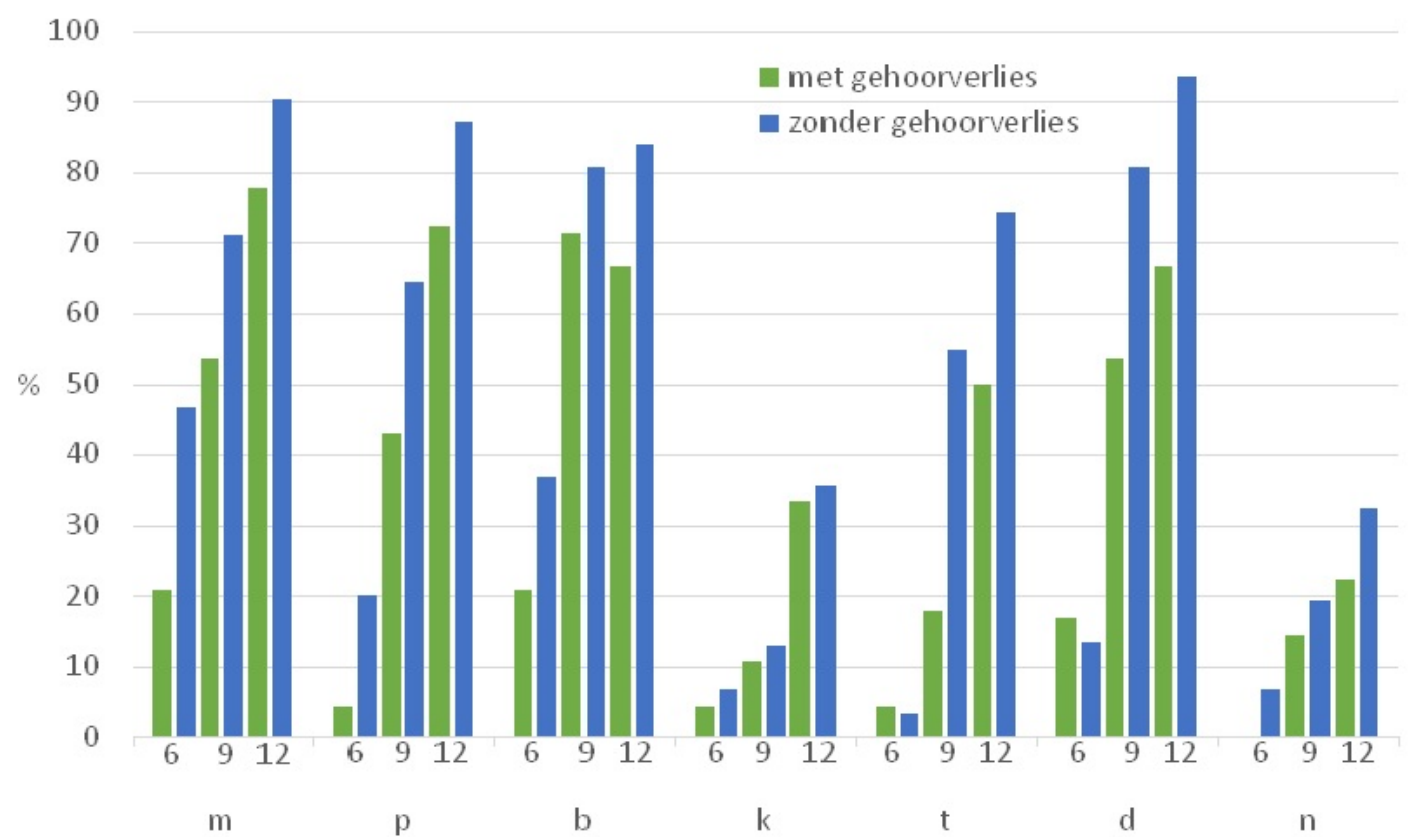

Figuur 6: Percentage kinderen dat consonanten produceerde op 6, 9 en 12 maanden. 
Tabel 3: Gemiddelde draagduur van hoortoestellen per dag in uren

\begin{tabular}{lll}
\hline Meetmoment & Volgens ouders & Datalogging \\
\hline 6 mnd & $3,7(\mathrm{~N}=21)$ & $3,1(\mathrm{~N}=16)$ \\
9 mnd & $4,1(\mathrm{~N}=23)$ & $3,8(\mathrm{~N}=10)$ \\
$12 \mathrm{mnd}$ & $5,2(\mathrm{~N}=16)$ & $4,0(\mathrm{~N}=7)$ \\
\hline
\end{tabular}

onderzocht of er sprake is van mediatie. Op de eerste plaats werd een indirect verband tussen mate van gehoorverlies en plafondvraag verwacht, gemedieerd door de hoorontwikkeling. Omdat op de leeftijd van 12 maanden slechts voor 12 kinderen alle gegevens beschikbaar waren, is het mediatiemodel alleen voor de leeftijd van 9 maanden getoetst $(n=20)$. Met behulp van regressieanalyses zijn de verschillende paden in het model getoetst (Figuur 7) om vast te stellen of er inderdaad sprake was van mediatie. Er bleek een significant verband te zijn tussen de mate van het gehoorverlies en de hoorontwikkeling (pad a) $(t=-4.89$, $p<.001$ ). Vervolgens is het verband tussen de hoorontwikkeling en de klankontwikkeling onderzocht, waarbij gecorrigeerd werd voor de invloed van de mate van gehoorverlies (pad b). Daaruit bleek een directe invloed van de hoorontwikkeling op de klankontwikkeling ( $t$ $=2.18, p=.044$ ). Daarna is onderzocht wat de directe invloed van de mate van gehoorverlies op de klankontwikkeling was, waarbij gecorrigeerd werd voor hoorontwikkeling (pad $\left.c^{\prime}\right)$. De mate van gehoorverlies bleek dan niet direct bij te dragen aan het verklaren van de klankontwikkeling $(t=-0.55, p=.592$, terwijl dit wel het geval was als er niet gecorrigeerd werd voor hoorontwikkeling (pad c) $(t=-2.81, p=.011)$. Dat het effect van de mate van gehoorverlies lager was wanneer gecorrigeerd werd voor de hoorontwikkeling geeft aan dat er mogelijk sprake is van mediatie (Baron \& Kenny, 1986). Om het indirecte pad via de mediator te toetsen is tot slot de Sobel test (Preacher \& Leonardelli, 2001) uitgevoerd. Hieruit bleek dat het gemedieerde effect significant was $(t=1.99, p=.046)$, wat betekent dat de mate van gehoorverlies invloed heeft op de hoorontwikkeling en de hoorontwikkeling vervolgens invloed heeft op de klankontwikkeling.

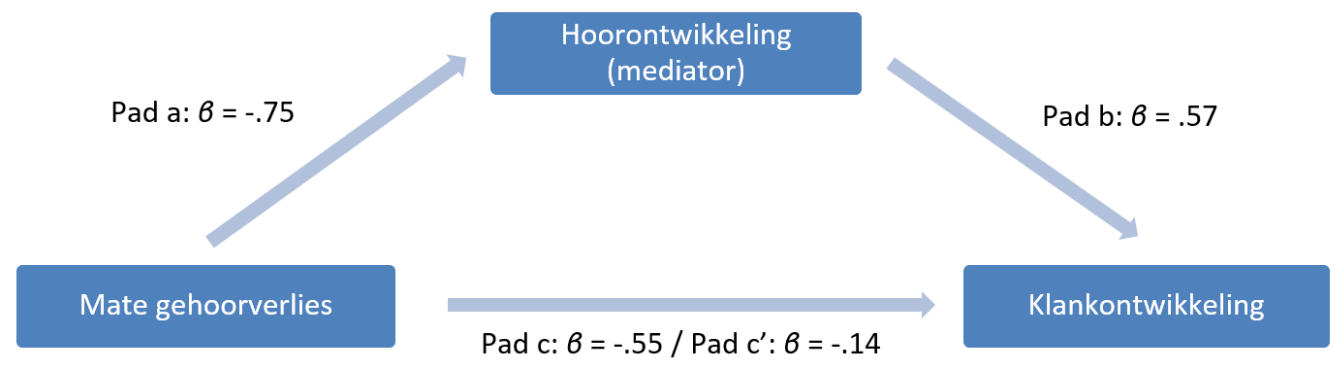

Figuur 7: Mediatiemodel met regressiecoëfficiënten.

Op de tweede plaats werd verwacht dat draagduur en leeftijd waarop gestart werd met 
gebruik van de hoortoestellen invloed had op de sterkte van de relatie tussen de mate van gehoorverlies en de hoorontwikkeling (moderatie) Ook dit is onderzocht voor de leeftijd van 9 maanden. Voor deze analyse is de draagduur volgens ouders meegenomen, aangezien hier meer gegevens van beschikbaar waren dan op basis van datalogging. Daarbij was de correlatie tussen datalogging gegevens en gegevens van ouders op 9 maanden matig tot sterk (.70).

Als eerste zijn de correlaties berekend tussen de draagduur en de mate van gehoorverlies ( $r=-.35, p=.107)$ en tussen de draagduur en de hoorontwikkeling $(r=.42, p=.045)$, waarbij alleen de laatste significant bleek. Vervolgens is de groep kinderen in tweeën gesplitst op basis van de mediaan (middelste score) in de groepen 'lage draagduur' $(M=1.3, S D=1.5$, range $=0-4$ uur) en 'hoge draagduur' $(M=6.0, S D=1.6$, range $=4.3-9.4$ uur). Daarna is voor beide groepen kinderen de correlatie tussen de mate van gehoorverlies en de hoorontwikkeling berekend. Bij zowel kinderen die het hoortoestel weinig droegen als kinderen die het hoortoestel veel droegen was een minder ernstig verlies gerelateerd aan een betere hoorontwikkeling (resp. $r=-.66, p=.037$ en $r=-.72, p=.019$ ). Bij toetsing bleken de sterktes van deze correlaties niet significant van elkaar te verschillen, het verband tussen mate van verlies en hoorontwikkeling was in beide groepen even sterk en er was dus geen sprake van moderatie.

Ten tweede is onderzocht of de leeftijd start hoortoestel invloed had op de relatie tussen de mate van gehoorverlies en de hoorontwikkeling. De correlaties van startleeftijd hoortoestel met de mate van gehoorverlies $(r=-.21, p=.399)$ en met de hoorontwikkeling $(r=.08, p$ $=.766$ ) waren niet significant. Vervolgens is ook hier op basis van de mediaan een tweedeling gemaakt in 'vroege start' $(M=2,9, S D=0.5$ range $=2.2-3.6$ maanden) en 'late start' $(M=$ $5.6, S D=3.5$, range $=3.9-15$ maanden). Hieruit bleek voor de groep kinderen die op relatief vroege leeftijd gestart was met hoortoestellen dat een minder ernstig verlies samenhing met een betere hoorontwikkeling $(r=-.83, p=.005)$ terwijl dit verband niet significant was voor de groep kinderen die hun eerste hoortoestel op latere leeftijd had gekregen $(r=-.67, p=$ .102). In deze laatste groep was beduidend meer spreiding. Na toetsing bleek dat er geen significant verschil tussen de sterkte van beide correlaties was, het verband tussen mate van verlies en hoorontwikkeling was in beide groepen dus even sterk en er was dus geen sprake van moderatie.

\section{Discussie}

Het doel van het huidige onderzoek was om zicht te krijgen op het verloop van de klankontwikkeling bij de huidige generatie Nederlandse kinderen met gehoorverlies en te onderzoeken welke factoren van invloed zijn op de klankontwikkeling bij deze groep kinderen. Uit dit onderzoek bleek met betrekking tot het eerste doel, dat kinderen met gehoorverlies op 9 maanden een achterstand in de klankontwikkeling hadden ten opzichte van kinderen zonder gehoorverlies. Tot de leeftijd van 5 à 6 maanden wordt de klankontwikkeling bepaald door de anatomische en fysiologische ontwikkeling (Cantle Moore, 2014), wat verklaart waarom er op 6 maanden geen verschil werd gevonden tussen kinderen met en zon- 
der gehoorverlies wat betreft het niveau van de klankontwikkeling zoals gemeten met de plafondvraag van de IMP. Hoewel er op 9 maanden wel een significant verschil werd gevonden, was dat verschil er niet meer op de leeftijd van 12 maanden. Dit kan verklaard worden doordat de IMP ontwikkeld is om de klankontwikkeling tot de leeftijd van 12 maanden (bij kinderen zonder gehoorverlies) in kaart te brengen. Veel kinderen zonder gehoorverlies hadden op deze leeftijd het eind van de vragenlijst reeds bereikt waardoor hun verdere ontwikkeling niet meer in kaart gebracht kon worden.

Kinderen met gehoorverlies lieten als groep een heterogener beeld zien in het verloop van de klankontwikkeling dan kinderen zonder gehoorverlies. Sommige kinderen lieten een snelle toename zien, bij andere kinderen was de toename meer gestaag of vlakte deze af. Bij enkele kinderen was er zelfs een achteruitgang in de klankontwikkeling te zien. Dit betrof de kinderen met een (zeer) ernstig gehoorverlies en ondersteunt de aanname dat tot 6 maanden de klankontwikkeling bepaald wordt door de anatomische en fysiologische ontwikkeling, maar vanaf 9 maanden het gemis van auditieve feedback tot uiting komt.

Behalve naar de bereikte plafondvraag op de IMP is er ook gekeken naar de variatie in $\mathrm{CV}$-combinaties als maat voor de klankontwikkeling. In overeenstemming met eerder onderzoek (Cantle Moore, 2014; Moeller e.a., 2007) bleek uit deze studie dat kinderen met gehoorverlies op zowel 6, 9 als 12 maanden gemiddeld minder verschillende CV-combinaties maakten dan kinderen zonder gehoorverlies. Wanneer gekeken werd naar de consonanten en vocalen die voorkwamen in de CV-combinaties dan bleken er bijna geen verschillen te zijn tussen de groepen. Het lijkt erop dat zowel de consonanten als de vocalen in grote lijnen in dezelfde volgorde en in hetzelfde tempo verworven werden in beide groepen, maar dat kinderen met gehoorverlies minder variëren in het combineren van de klanken dan horende kinderen.

Het tweede doel van deze studie was te onderzoeken welke factoren gerelateerd zijn aan de klankontwikkeling van kinderen met gehoorverlies. Uit onze resultaten bleek dat de mate van gehoorverlies invloed had op de klankontwikkeling. Er was echter sprake van een indirecte invloed via hoorontwikkeling. Een hogere mate van gehoorverlies leidde in dit onderzoek tot een minder goede hoorontwikkeling en daardoor tot een minder goede klankontwikkeling. Het belang van het stimuleren van een goede hoorontwikkeling wordt hier nogmaals onderstreept.

Een factor die kan bijdragen aan het stimuleren van de hoorontwikkeling is de draagduur. Uit de resultaten bleek dat het veel dragen van het hoortoestel samenging met een betere hoorontwikkeling, wat het belang laat zien van goede hoorinterventie. De hypothese was echter dat draagduur en leeftijd waarop gestart was met de hoortoestellen de relatie tussen mate van verlies en de hoorontwikkeling zou beïnvloeden. Dit werd echter niet bevestigd. Mate van verlies was van invloed op de hoorontwikkeling ongeacht of hoortoestellen veel of weinig gedragen werden en er vroeg of laat gestart was met de hoortoestellen. In andere woorden, uit deze studie blijkt dat een kind met een ernstig verlies een groter risico loopt dan een kind met een minder ernstig verlies op een achterblijvende hoorontwikkeling, ook als vroeg gestart is met hoortoestellen en deze veel gedragen worden. De invloed van de mate van verlies kan niet volledig teniet worden gedaan door een goede hoorinterventie maar veel dragen van de hoortoestellen heeft wel degelijk een positief effect op de 
hoorontwikkeling en daarmee op de klankontwikkeling.

Behalve (voorlopige) antwoorden op de onderzoeksvragen heeft deze studie bijkomende bevindingen opgeleverd. Een van deze bevindingen is dat ouders de draagduur van de hoortoestellen vaak lijken te overschatten. Dit bleek uit een vergelijking tussen de gemiddelde draagduur per dag in uren zoals die door ouders werd gerapporteerd en de gegevens die middels datalogging uitgelezen werden uit de hoortoestellen bij een bezoek aan het audiologisch centrum. In eerder onderzoek is ook gebleken dat ouders eerder een over- dan een onderschatting geven van hoeveel het hoortoestel gedragen wordt (Walker e.a., 2013). Bewustwording van ouders hiervan, door dit op het audiologisch centrum of vanuit de gezinsbegeleiding met ouders te bespreken, lijkt een belangrijk aandachtspunt in de behandeling.

Een andere bijkomende bevinding in dit onderzoek was dat ouders aangaven zich na de afname van de IMPs veel meer bewust te worden van de klankontwikkeling en van de kleine stapjes die het kind gedurende de periode die ze gevolgd werden lieten zien dan daarvoor. Door de interviews gaven ouders aan veel meer te letten op combinaties van klanken en protowoorden die het kind liet horen. Over het algemeen hebben ouders het als positief en waardevol ervaren om te ontdekken wat hun kind al kan. Dit is inherent aan hoe de IMP is opgezet, waarbij bij elk meetmoment steeds verder wordt gegaan vanaf het punt waar het kind de vorige keer was gebleven in diens ontwikkeling. Ouders merkten zo (in de meeste gevallen) dat hun kind alweer meer kon dan de vorige keer.

Dit onderzoek kende ook een aantal beperkingen. Een van de belangrijke beperkingen is de kleine onderzoeksgroep, waardoor door een gebrek aan power een grotere kans op type II fouten ontstaat. Voor het vergelijken van het verloop van de klankontwikkeling van kinderen met en zonder gehoorverlies waren de groepen groot genoeg. Maar om goed naar de invloed van verschillende onderliggende factoren op de klankontwikkeling te kijken waren eigenlijk meer participanten nodig geweest en een meer evenredige verdeling wat betreft mate van gehoorverlies (Voorhis \& Morgan, 2007). Meer onderzoek in Nederland, maar ook internationaal, is nodig om de invloed van deze factoren verder vast te stellen. Bij het interpreteren van de resultaten moet daarnaast rekening gehouden worden met het feit dat het merendeel van de kinderen middenoorproblemen heeft gehad, welke tijdelijk voor een grotere mate van gehoorverlies konden zorgen. Dit geldt echter zowel voor de kinderen met als zonder gehoorverlies.

Samenvattend blijkt uit dit onderzoek dat er al in het eerste jaar een achterstand ontstaat in de klankontwikkeling bij kinderen met gehoorverlies. Opvallend zijn de grote individuele verschillen binnen de groep kinderen met gehoorverlies. Dit betekent in ieder geval dat een deel van de jonge kinderen met gehoorverlies een suboptimale klankontwikkeling doorloopt. Het zou professionals extra informatie kunnen geven wanneer ze de klankontwikkeling bij kinderen met gehoorverlies volgen en nagaan of deze passend is bij de draagtijd van de hoortoestellen en de hoorontwikkeling van het kind. Dit geeft hen aanknopingspunten om met ouders in gesprek te gaan over de klankontwikkeling en hoe ze deze kunnen stimuleren, in overeenstemming met de hoormogelijkheden van het kind. 


\section{Referenties}

Ambrose, S. E., Thomas, A., \& Moeller, M. P. (2016). Assessing vocal development in infants and toddlers who are hard of hearing: A parent-report tool. Journal of Deaf Studies and Deaf Education, 21(3), 237-248. https://doi.org/10.1093/deafed/enw027

Baron, R. M., \& Kenny, D. A. (1986). The moderator mediator variable distinction in social psychological research: Conceptual, strategic, and statistical considerations. Journal of Personality and Social Psychology, 51(6), 1173-1182. https://doi.org/10.1037/00223514.51.6.1173

Beers, M. (2003). Klankproductieproblemen: een fonologische benadering. Stem-, Spraaken Taalpathologie, 11(4), 245-259.

Boons, T., Brokx, J. P. L., Dhooge, I., Frijns, J. H. M., Peeraer, L., Vermeulen, A., . . . Van Wieringen, A. (2012). Predictors of spoken laguage development following pediatric cochlear implantation. Ear and Hearing, 33, 617-639.

Cantle Moore, R. (2008). Infant monitor of vocal production. North Rocks, Australia: RIDBC Renwick Centre.

Cantle Moore, R. (2012). The ABC of IMP: IMPlementing the Infant Monitor of vocal Production. Paper presented at the FCEI, Bad Ischl, Austria.

Cantle Moore, R. (2014). The infant monitor of vocal production: Simple beginnings. Deafness \& Education International, 16(4), 218-236. https://doi.org/10.1179/1464315414Z.00000000067

Cantle Moore, R., \& Colyvas, K. (2018). The Infant Monitor of vocal Production (IMP) normative study: important foundations. Deafness \& Education International, 20(3-4), 228-244. https://doi.org/10.1080/14643154.2018.1483098

Ching, T. Y. C., Dillon, H., Marnane, V., Hou, S. N., Day, J., Seeto, M., . . Y Yeh, A. (2013). Outcomes of early- and late-identified children at 3 years of age: Findings from a prospective population-based study. Ear and Hearing, 34(5), 535-552.

https://doi.org/10.1097/AUD.0b013e3182857718

Coninx, F., Weichbold, V., Tsiakpini, L., Autrique, E., Bescond, G., Tamas, L., . . . Le ManerIdrissi, G. (2009). Validation of the LittlEARS $®$ Auditory Questionnaire in children with normal hearing. International Journal of Pediatric Otorhinolaryngology, 73(12), 17611768.

Ertmer, D. J., Young, N. M., \& Nathani, S. (2007). Profiles of vocal development in young cochlear implant recipients. Journal of Speech Language and Hearing Research, 50(2), 393-407. https://doi.org/10.1044/1092-4388(2007/028)

Iyer, S. N., \& Oller, D. K. (2008). Prelinguistic vocal development in infants with typical hearing and infants with severe-to-profound hearing loss. Volta Review, 108(2), 115138.

Koopmans-van Beinum, F. J., Clement, C. J., \& van den Dikkenberg-Pot, I. (2001). Babbling and the lack of auditory speech perception: a matter of coordination? Developmental Science, 4(1), 61-70. https://doi.org/10.1111/1467-7687.00149

Kühn-Inacker, H., Weichbold, V., Tsiakpini, L., Coninx, S., \& D’Haese, P. (2003). LittlEARS® Auditory Questionnaire. Innsbruck, Austria: MED-EL Corporation. 
Lederberg, A. R., Schick, B., \& Spencer, P. E. (2013). Language and literacy development of deaf and hard-of-hearing children: Successes and challenges. Developmental Psychology, 49(1), 15-30. https://doi.org/10.1037/a0029558

Leigh, J., Dettman, S., Dowell, R., \& Briggs, R. (2013). Communication development in children who receive a cochlear implant by 12 months of age. Otology \& Neurotology, 34(3), 443-450. https://doi.org/10.1097/MAO.0b013e3182814d2c

Litovsky, R. (2015). Development of the auditory system. Handbook of clinical neurology (Vol. 129, pp. 55-72): Elsevier.

McCreery, R. W., Bentler, R. A., \& Roush, P. A. (2013). Characteristics of hearing aid fittings in infants and young children. Ear and Hearing, 34(6), 701-710. https://doi.org/10.1097/AUD.0b013e31828f1033

Moeller, M. P., Hoover, B., Peterson, B., \& Stelmachowicz, P. (2009). Consistency of hearing aid use in infants with early-identified hearing loss. American Journal of Audiology, 18(1), 14-23. https://doi.org/10.1044/1059-0889(2008/08-0010)

Moeller, M. P., Hoover, B., Putman, C., Arbataitis, K., Bohnenkamp, G., Peterson, B., . . . Stelmachowicz, P. (2007). Vocalizations of infants with hearing loss compared with infants with normal hearing: part I - Phonetic development. Ear and Hearing, 28(5), 605-627. https://doi.org/10.1097/AUD.0b013e31812564ab

Molemans, I. (2011). Sounds like babbling. A longitudinal investigation of aspects of the prelexical speech repertoire in young children acquiring Dutch: Normally hearing children and hearing-impaired children with a cochlear implant. Universiteit Antwerpen.

Niparko, J. K., Tobey, E. A., Thal, D. J., Eisenberg, L. S., Wang, N.-Y., Quittner, A. L., . . . CDaCI Investigative Team. (2010). Spoken language development in children following cochlear implantation. Journal of the American Medical Association, 303(15), 14981506.

Oller, D. K., Eilers, R. E., Neal, A. R., \& Schwartz, H. K. (1999). Precursors to speech in infancy: The prediction of speech and language disorders. Journal of Communication Disorders, 32(4), 223-245. https://doi.org/10.1016/s0021-9924(99)00013-1

Preacher, K. J., \& Leonardelli, G. J. (2001). Calculation for the Sobel test.

Schaerlaekens, A. M., \& Gillis, S. (1987). De taalverwerving van het kind. Groningen: WoltersNoordhoff.

Schauwers, K., Gillis, S., Daemers, K., De Beukelaer, C., \& Govaerts, P. J. (2004). Cochlear implantation between 5 and 20 months of age: The onset of babbling and the audiologic outcome. Otology \& Neurotology, 25(3), 263-270. https://doi.org/10.1097/00129492200405000-00011

Sininger, Y. S., Grimes, A., \& Christensen, E. (2010). Auditory development in early amplified children: Factors influencing auditory-based communication outcomes in children with hearing loss. Ear and Hearing, 31(2), 166.

Tomblin, J. B., Harrison, M., Ambrose, S. E., Walker, E. A., Oleson, J. J., \& Moeller, M. P. (2015). Language outcomes in young children with mild to severe hearing loss. Ear and Hearing, 36, 76S-91S.

Uilenburg, N., \& Van der Zee, R. (2014). Neonatale gehoorscreening: Aanvang van interventie bij jonge kinderen met een gehoorverlies geboren in 2012. NSDSK in opdracht van 
RIVM.

Vohr, B., Jodoin-Krauzyk, J., Tucker, R., Johnson, M. J., Topol, D., \& Ahlgren, M. (2008). Early language outcomes of early-identified infants with permanent hearing loss at 12 to 16 months of age. Pediatrics, 122(3), 535-544. https://doi.org/10.1542/peds.2007-2028

VanVoorhis, C. W., \& Morgan, B. L. (2007). Understanding power and rules of thumb for determining sample sizes. Tutorials in quantitative methods for psychology, 3(2), 4350. https://doi.org/10.20982/tqmp.03.2.p043

Wake, M., Hughes, E. K., Poulakis, Z., Collins, C., \& Rickards, F. W. (2004). Outcomes of children with mild-profound congenital hearing loss at 7 to 8 years: A population study. Ear and Hearing, 25(1), 1-8. https://doi.org/10.1097/01.aud.0000111262.12219.2f

Walker, E. A., McCreery, R. W., Spratford, M., Oleson, J. J., Van Buren, J., Bentler, R., . . . Moeller, M. P. (2015). Trends and predictors of longitudinal hearing aid use for children who are hard of hearing. Ear and Hearing, 36, 38S-47S.

Walker, E. A., Spratford, M., Moeller, M. P., Oleson, J., Ou, H., Roush, P., \& Jacobs, S. (2013). Predictors of hearing aid use time in children with mild-to-severe hearing loss. Language Speech and Hearing Services in Schools, 44(1), 73-88.

https://doi.org/10.1044/0161-1461(2012/12-0005) 